\title{
ARTIKELEN
}

\section{Criminaliteit en macht: een inleiding}

\author{
René van Swaaningen
}

De term 'crimes of the powerful' kunnen we het beste begrijpen als een 'sensitising concept'; een lens waarmee we de dimensie van het structurele machtsoverwicht bij uiteenlopende laakbare gedragingen benadrukken. Naast de ongelijke machtsrelatie tussen dader en slachtoffer zoomt de 'crimes of the powerful'-lens tevens in op de gebrekkige criminalisering van dergelijke gedragingen en om het gemak waarmee de daders ermee weg kunnen komen. We komen het begrip als zodanig voor het eerst tegen in het boek Crimes of the Powerful: Marxism, Crime and Deviance dat Frank Pearce in 1976 schreef. In meer impliciete zin wordt het begrip ook gehanteerd in het werk van Herman en Julia Schwendinger (1970: 168-9). In hun klassieke essay 'Defenders of Order or Guardians of Human Rights' hadden zij het over de 'practices of those in power who are seriously harmful to most of humanity and are not defined and sanctioned by civil or criminal laws, such as genocide and economic exploitation'.

Dit wil niet zeggen dat het idee 'crimes of the powerful' dus een Angelsaksische uitvinding is. Hoewel marxistische perspectieven in de Nederlandse criminologie weinig populair zijn, spelen auteurs uit de Lage Landen juist een vrij centrale rol in het debat over vanwege een machtsoverwicht gepleegde delicten. Willem Nagel (1976) sprak, in navolging van Johan Galtungs ideeën over structureel geweld, over criminaliteit in termen van 'over-powering' en hij bekritiseerde het feit dat bijvoorbeeld de wandaden die worden gepleegd door militaire regimes vaak niet eens strafbaar zijn, noch enige aandacht krijgen van criminologen. Herman Bianchi (1980) beschouwde de laakbare praktijken van gezagsdragers zelfs als de misdaden bij uitstek. En in zijn studies over primaire criminalisering heeft Patrick Hebberecht (1984) gewezen op een keur aan auteurs uit België en Nederland die al vroeg de aandacht hebben gevestigd op de (bewust) niet-gecriminaliseerde wandaden van mensen uit de hogere sociale klassen. De Fransen hebben er zelfs een eigen begrip voor ontwikkeld: élites délinquantes (Lascoumes, 2013). Het feit dat je deze studies niet vindt als je 'crimes of the powerful' als zoekterm hanteert, is een gevolg van het Engelstalige imperialisme in de hedendaagse wetenschap.

Dat het niet zo evident is om over criminaliteit te spreken als een uitvloeisel van het feit dat men eenvoudigweg de macht heeft om anderen de wil op te leggen, blijkt wanneer we constateren dat criminologen door de geschiedenis heen criminaliteit vooral hebben verklaard als een gevolg van tekortkomingen, of die nou medisch, (bio-)psychologisch, cognitief, sociaal of economisch van aard zijn. Hoewel zij de tekorten elders lokaliseren en anders duiden, onderscheidden linkse criminologen zich wat dit betreft niet van rechtse. In The Condition of the Working 
Class in England beschrijft Friedrich Engels (1845) dat de deplorabele toestand waarin de arbeidersklasse moet zien te overleven leidt tot een demoralisering. Als die voorbij een bepaald punt komt, dan is het volgens Engels niet meer dan natuurlijk dat de pauper zijn toevlucht neemt tot criminaliteit. Dat is volgens hem net zo onvermijdelijk als het feit dat water bij 100 graden gaat koken.

Willem Bonger (1905) bouwde hier in zijn theorie over de economische bepaaldheid van criminaliteit op voort. De sociale ellende waarin de werkende klasse zich bevindt, haalt niet het mooiste in mensen naar boven. Het kapitalisme leidt tot hebzucht en de beroerde omstandigheden waarin de arbeidersklasse moest zien te overleven, leidt volgens Bonger tot hun demoralisering en tot een verlies van de altruïstische moraal überhaupt. De morele verwaarlozing en slechte opvoeding van kinderen concentreert zich in de armste klassen, waardoor een criminogene structuur hier in de generaties wordt doorgegeven. Bonger verwachtte dat een groot deel van de 'criminaliteit uit ellende' zal verdwijnen indien de sociale omstandigheden verbeteren, maar er zal altijd criminaliteit uit begeerte, in economische of seksuele zin, blijven bestaan. Bonger wijst in zijn studie ook op immorele en maatschappelijk schadelijke gedragingen van bijvoorbeeld bankiers en effectenhandelaren. Die worden niet als crimineel beschouwd, omdat handelingen die alleen de belangen van de gedomineerde klassen schaden nu eenmaal nooit als 'misdrijf' worden gedefinieerd. Met die constatering preludeert Bonger op het debat over 'crimes of the powerful'.

Twee jaar na Bonger gaat Edward Alsworth Ross (1907: 45-75) nog een stapje verder, door te stellen dat de schandalige praktijken waar gegoede burgers, met hun odium van respectabiliteit, religiositeit, filantropie en patriottisme, vaak eenvoudig mee wegkomen 'criminaloïde' te noemen. Over het recht zegt Ross: 'The law is a club to rescue your friends from and to smite your enemies with, but it has no claim of his own.' Ross stelt voorts dat het een morele zwakte is dat wij deze quasicriminelen niet veroordelen, terwijl wij de 'gewone' misdadiger wel in alle toonaarden veroordelen. Met zijn theorie over 'trusted criminals' wijst David Friedrichs (2010) zo'n honderd jaar later op een vergelijkbaar punt: witteboordencriminelen komen vaak weg met hun laakbare praktijken, omdat zij worden vertrouwd; omdat hun een bepaalde maatschappelijke respectabiliteit wordt toegedicht.

Er was aan het begin van de twintigste eeuw dus wel de nodige verontwaardiging over misdragingen van respectabel geachte burgers, maar grosso modo moeten we toch constateren dat het idee dat ook personen met macht en aanzien, mensen die volop kansen hebben gehad in het leven en die niets tekortkomen, óók crimineel zouden kunnen zijn, zelfs in de hoofden van de meest kritische denkers in de vroege criminologie nauwelijks voorkwam. In die zin was het idee dat er ook 'crimes of the powerful' waren lang een blinde vlek in de criminologie.

Hoezeer dat is veranderd, bleek wel toen ik in het tweedejaarsvak Grondslagen van de criminologie aan de Erasmus Universiteit Rotterdam naar aanleiding van de bovenstaande passage uit het werk van Friedrich Engels de vraag stelde of dit 
dan betekende dat arme mensen crimineler zijn dan rijke, vrijwel alle studenten dit ontkennend beantwoordden en erop wezen, dat de fabriekseigenaren die mensen zulke extreem lange werkdagen lieten maken voor een hongerloontje véél crimineler waren - net als Engels zelf overigens concludeerde.

Als het begrip 'macht' in de criminologie aan de orde kwam, dan ging het vooral over criminaliseringsmacht - al werd dat ook pas vanaf de jaren zeventig van de twintigste eeuw als zodanig gethematiseerd. Het debat over de reproductie en versterking van maatschappelijke ongelijkheid door middel van een selectieve criminalisering en berechting van arme mensen vindt zijn oorsprong in de analyse die Karl Marx in 1842, in de Rheinische Zeitung, maakte van de criminalisering van het gewoonterecht van de armen om sprokkelhout te verzamelen en te verkopen, door het van res nullius te herdefiniëren als bezit van de grondbezitter. Het is interessant om te zien hoe actueel dit essay nog is. Zo laat Tim Boekhout van Solinge (2010) zien hoe houthandelaren en sojaboeren in het Amazonegebied de inheemse bevolking zonder scrupules - en niet zelden (onder dreiging) met geweld - komen vertellen dat zij de eigenaren van het land zijn, omdat nergens staat geregistreerd dat het van de inheemse volkeren zou zijn en of die 'indianen' maar even hun biezen willen pakken. Iets vergelijkbaars zien we bij het geïnstitutionaliseerde landjepik van de Israëlische nederzettingenpolitiek in de Palestijnse gebieden.

Hoe vanzelfsprekend het voor criminologiestudenten in 2019 dan ook moge wezen dat er zoiets bestaat als 'crimes of the powerful', feit is dat het criminologen een flinke tijd heeft gekost om zich dit te realiseren. Het meest pijnlijke voorbeeld is misschien wel het feit dat zo ongeveer de grootste misdaad in de menselijke geschiedenis, slavernij, tot voor kort niet of nauwelijks door criminologen is gethematiseerd. Pas met pleidooien om de criminologie te dekoloniseren van haar westerse vooringenomenheden en het zodoende tot een mondiaal zinvollere tak van wetenschap te maken, is hier enige verandering in gekomen (Agozino, 2003).

Ook over andere massamisdrijven, oorlogsmisdaden, de Shoah in het bijzonder, zijn criminologen pas betrekkelijk laat gaan schrijven. De opsporingspraktijken van de Gestapo, de mede door biocriminologische inzichten geoptimaliseerde, mechanische uitroeiing van Joden, Roma en Sinti en homoseksuelen door de nazi's en de betrokkenheid van het bedrijfsleven hierbij ... het heeft criminologen tot ongeveer de laatste eeuwwisseling gekost voordat ze erover begonnen te schrijven. Hetzelfde geldt voor de onder Stalin gepleegde misdaden van de geheime politie in de Sovjet-Unie, de Cheka, de politieke strategie van de uithongering van 'opstandige' bevolkingsgroepen en het zich in de goelagarchipels laten doodwerken van miljoenen mensen (Fijnaut, 2014: hfdst.9). Romanschrijvers waren criminologen in dit opzicht ver vooruit.

Edwin Sutherland (1949: 514) is de geschiedenis ingegaan als de eerste criminoloog die de cruciale vraag stelde waarom mensen in machtsposities ook criminaliteit plegen: 


\begin{abstract}
'Respectable businessmen who violate the law are seldom in poverty and seldom manifest the social and personal pathologies. The General Motors Corporation does not violate the law because of an Oedipus complex, the General Electric Company because it is emotionally unstable, the Anaconda Copper Company because of bad housing conditions, Armour and Company because of a lack recreational facilities or any of them because of poverty.'
\end{abstract}

Daarom, stelt Sutherland, moeten we witteboordencriminaliteit verklaren als uitkomst van een sociaal leerproces: zakenmensen leren elkaar als het ware dat de kluit belazeren niet zo erg is als het bedrijfsbelang ermee is gediend. Zijn differentiële associatietheorie is nog geen theorie over 'crimes of the powerful', maar Sutherland verdient het wel om als pionier hiervan te worden genoemd, ook omdat zijn naam het meest nadrukkelijk is verbonden met de stelling dat het begrip 'criminaliteit' niet aan wettelijke definities kan worden gebonden, simpelweg omdat een deel van het probleem is dat de wetgever vaak een blinde vlek heeft om de gedragingen van 'respectabele' personen te criminaliseren.

Ook de hedendaagse discussie over witteboordencriminaliteit, tegenwoordig eerder 'corporate crime' of organisatiecriminaliteit genoemd, valt lang niet altijd onder de noemer 'crimes of the powerful' te vatten, omdat het in deze studies meestal als een ongelukkige uitzondering wordt beschouwd in plaats van als een uitvloeisel van de enorme macht die bedrijven hebben om de wereld naar hun hand te zetten en politici en regelgeving te beïnvloeden. Door de enorme macht die lobbyisten uit de auto-, tabaks-, olie-, chemische of voedingsindustrie hebben om voor hun bedrijfstak ongunstige wetgeving te blokkeren of wettelijke definities te beïnvloeden, zorgen zij ervoor dat deze industrieën hun gang kunnen gaan.

In haar recente boek Marxism and Criminology: A History of Criminal Selectivity beschrijft de Argentijnse criminologe Valeria Vegh Weis (2018) 'macht' als het mechanisme dat zowel leidt tot een over-criminalisering van misdragingen van 'machtelozen' (powerless), als tot een onder-criminalisering van maatschappelijk schadelijke gedragingen van de 'machtigen' (de powerful).

We kunnen niet goed over de overgang van de discussie over witteboordencriminaliteit in termen van 'crimes of the powerful' schrijven zonder het werk van C. Wright Mills te noemen. In zijn boek White Collar Crime: The American Middle Classes uit 1951 politiseert hij Sutherlands begrip door de toenemende invloed van het 'middle management' op de inrichting van de samenleving te benadrukken. Maar Mills' bijdrage aan het denken over 'crimes of the powerful' werd pas goed duidelijk met het verschijnen van zijn boek The Power Elite uit 1956. In dit boek laat Mills zien hoe de belangen van militaire, bedrijfseconomische en politieke leiders vaak hand in hand gaan en hoe machteloos 'normale burgers' in dit krachtenveld meestal zijn.

De term 'crimes of the powerful' is eind jaren zeventig van de vorige eeuw gangbaar geworden in de criminologie, toen zij werd geïntroduceerd door kritische criminologen die meenden dat 'mainstream' criminologen veel te dicht tegen het 
overheidsdiscours over criminaliteit aan schurkten en te weinig vragen stelden over de criminogene werking van machtsverhoudingen. De pijlen werden vooral gericht op overheidsmacht en op de macht van het bedrijfsleven. Een bekende frase in dit verband was, dat criminologen eens wat minder door de ramen van politiewagens naar de samenleving zouden moeten kijken en eens wat meer naar wat er in die politiewagens gebeurt. Het was de tijd waarin 'de autoriteiten' in brede zin onder vuur kwamen te liggen, gezag niet meer voetstoots werd geaccepteerd en excessief overheidsingrijpen op warme belangstelling van onderzoekers kon rekenen.

Het boek waarin de diverse blinde vlekken van criminologen genadeloos onder de loep werden genomen, is zonder meer The New Criminology van Ian Taylor, Paul Walton en Jock Young (1973). Al spoedig bleek echter dat er na hun analyses toch nog wel wat blinde vlekken waren overgebleven. Nota bene een promovenda van Ian Taylor, Carol Smart (1976), signaleerde dat deze kritische heren wel heel weinig oog hadden voor criminogene structuren die in ongelijke genderverhoudingen besloten liggen. Nadat Smart met haar boek Women, Crime and Criminology de piketpalen had geslagen, volgde een bloeiende feministische criminologie waarin de aandacht werd gevestigd op 1) de problematische (seksualiserende) wijzen waarop mannen hun 'macht' over vrouwen doen gelden, en 2) hoe weinig hier door politie en justitie aan wordt gedaan. Later is dit uitgebreid tot seksuele intimidatie in een breed scala van afhankelijkheidsrelaties: binnen gezinnen, in het onderwijs, in arbeidsrelaties, et cetera. De huidige \#metoo-discussie is ook een uitvloeisel van het feit dat het structurele overwicht van mannen, zowel fysiek als op de arbeidsmarkt, en de nog steeds vaak ondergeschikte positie van vrouwen, door feministische criminologen in de jaren zeventig op de agenda zijn gezet. Tegelijkertijd moeten we constateren dat structurele genderongelijkheid nog steeds een vrij beperkte rol speelt in het debat over 'crimes of the powerful', en dat terwijl actuele discussies over seksueel misbruik in de Rooms-Katholieke Kerk of in de jeugdzorg' ${ }^{1}$ uitstekend door middel van de lens van 'crimes of the powerful' zouden kunnen worden verklaard.

Nadat vrouwen hun posities in de academie hadden ingenomen, kwam ook de discussie over racisme en andere hate crimes op de criminologische agenda. Hierbij dient te worden aangetekend, dat, waar de feministische criminologie vanaf de jaren zeventig een enorme vaart heeft genomen, onderzoek naar racisme en etnisch profileren door politie en justitie nog steeds zelden als structureel verschijnsel aan de kaak wordt gesteld, maar, als het al wordt onderzocht, eerder als een 'schoonheidsfoutje' van een verder rechtvaardig systeem wordt gezien dan als

1 Respectievelijk www.rkkerk.nl/dossiers/dossier-misbruik en www.rijksoverheid.nl/actueel/ nieuws/2019/06/12/eindrapport-commissie-onderzoek---de-winter-kinderen-werdenvanaf-1945-in-de-jeugdzorg-onvoldoende-beschermd-tegen-geweld. 
een uitvloeisel van ongelijke etnische verhoudingen, wat het bezien door de lens van 'crimes of the powerful' is. ${ }^{2}$

Van nog later datum is de term 'state crime' (Chambliss, 1989). Penny Green en Tony Ward (2004) definiëren 'state crime' als 'illegal or deviant activities perpetrated by, or with, the complicity of state agencies'. Het betreft een breed scala aan overheidshandelen, zoals collusie en corruptie, institutionele discriminatie, steun aan of financiering van 'terroristen' of paramilitairen, oorlogsmisdaden, marteling, actief of passief bijdragen aan ontvoering of moord, genocide, et cetera. Het is evident dat naarmate een Staat machtiger is en meer in het centrum van de mondiale machtsverhoudingen staat, de betrokkenheid bij 'state crime' toeneemt. 'State crime' is ook een van de moeilijkste begrippen in de criminologie, enerzijds omdat de overheid zelf de belangrijkste definitiemacht heeft en het eigen handelen nooit 'crimineel' zal noemen en anderzijds omdat het bij 'state crime' bijzonder moeilijk is om concrete, individuele daders aan te wijzen (Brants, 2007).

Met de opkomst van groene criminologie is de discussie over organisatiecriminaliteit steeds meer in termen van 'crimes of the powerful' gevoerd, ook omdat de belangrijkste daders van de meest ernstige vormen van ecologische criminaliteit grote bedrijven zijn. Denk hierbij aan ontbossing en het vergiftigen van de leefomgeving en aan voedselgiganten als Cargill of Monsanto en aan chemische bedrijven als Union Carbide. Iets vergelijkbaars kan worden opgemerkt met betrekking tot onderzoek naar de betrokkenheid van het bedrijfsleven bij misdrijven tegen de menselijkheid: van de bedrijven die de ovens voor de gaskamers in de nazivernietigingskampen hebben gebouwd tot de bedrijven die werknemers die lid waren van een vakbond hebben uitgeleverd aan de militaire junta's in Latijns-Amerikaanse landen in de late jaren zeventig en tachtig van de vorige eeuw.

Juist vanwege het feit dat het bij 'crimes of the powerful' vaak om niet in wetgeving strafbaar gesteld gedrag gaat en de rechtsmacht vanwege het internationale karakter ervan vaak onduidelijk is, waardoor de machtige daders de dans ook vaak weten te ontspringen, hebben criminologen rond de afgelopen eeuwwisseling voorgesteld om bij 'crimes of the powerful' niet langer de daders centraal te stellen, maar te bekijken hoe de schade van deze gedragingen zo veel mogelijk kan worden beperkt dan wel hersteld (Hillyard e.a., 2004). Binnen deze

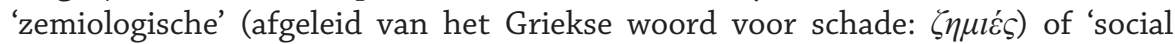
harm'-benadering vindt de moralisering van door machtige partijen gepleegde maatschappelijk schadelijke gedragingen veelal plaats door 'naming and shaming' en 'blacklisting' in plaats door middel van strafrechtelijke sancties. Volgens de

2 De recente ophef over Haagse politieagenten die zich als 'Marokkanenverdelgers' presenteerden en dat de teamchef van de politie Haaglanden - Fatima Aboulouafa - die hier tegen in het geweer kwam vervolgens op non-actief is gesteld, spreekt in dit verband boekdelen. Zie www.nrc.nl/ nieuws/2019/09/13/op-politiebureau-hoefkade-heersen-discriminatie-geweld-en-eenongezonde-cultuur-a3973310. 
Franse criminoloog Pierre Lascoumes (2013) is het feit dat 'delinquente elites', onder meer in de media en in de politieke arena, zo goed in staat zijn de ernst van de tegen hen ingebrachte feiten te bagatelliseren en hun eigen verantwoordelijkheid te minimaliseren echter een reden dat zij zo weinig vatbaar zijn voor effectieve labelling. Beschuldigingen glijden als het ware van hen af als waren zij, zoals Lascoumes over de Nederlandse premier Mark Rutte opmerkt, voorzien van een teflonlaag.

De corrumperende werking van macht, gezag en aanzien komt, hoewel hij in paradigmatische zin wel uit een ander vaatje tapt dan de kritische criminologen, ook nadrukkelijk aan bod in de controle balans-theorie van Charles Tittle (1995). Criminaliteit treedt volgens Tittle op wanneer mensen te veel een object van sociale controle zijn - ergo wanneer zij hun stigma internaliseren en secundair deviant gedrag vertonen - maar óók wanneer de balans naar de andere kant uitslaat; wanneer niemand het meer aandurft bepaalde personen op hun gedrag aan te spreken of hen ter verantwoording te roepen. De overmoed en arrogantie die daardoor ontstaat, geeft dergelijke mensen het gevoel dat ze overal mee weg kunnen komen.

Inmiddels is er al behoorlijk wat empirisch onderzoek naar 'crimes of the powerful' gedaan. De verschijning van een maar liefst 556 bladzijden tellend Routledge International Handbook of the Crimes of the Powerful is hier een uitdrukking van (Barak, 2015). In dit boek worden eerst in negen hoofdstukken de cultuur en de ideologie van 'crimes of the powerful', en de rol die mondialisering ('globalization') hierbij speelt, onder de loep genomen en vervolgens komen in twintig hoofdstukken verschijningsvormen als organisatiecriminaliteit, milieucriminaliteit, financiële criminaliteit, verschillende varianten van 'state crime' aan de orde. Het boek sluit af met acht flinke hoofdstukken over de vraag waarom de aanpak van 'crimes of the powerful' zoveel te wensen over laat. Voor wie een actueel overzicht van het onderzoek naar 'crimes of the powerful' wil krijgen, is dit boek een goudmijn.

Het boek Revisiting Crimes of the Powerful: Marxism, Crime and Deviance van Steven Bittle, Laureen Snider, Steve Tombs en David Whyte (2018) is vooral een eerbetoon aan Frank Pearce, die het begrip 'crimes of the powerful' in 1976 op de criminologische kaart heeft gezet. Het boek begint zelfs met een lang essay van Pearce, waarin hij autobiografische details koppelt aan zijn marxistische uitgangspunten. Verder heeft het boek een vergelijkbare opzet als het Routledge International Handbook, zij het dat het wordt voorafgegaan door een wat uitgebreider theoretisch deel, een nadrukkelijker kritiek op de neoliberale revolutie van de jaren 1990 bevat en dat het besproken onderzoek ook wat vaker over niet-Engelssprekende landen gaat. Het eveneens recent verschenen boek Crimes of the Powerful: An Introduction van Dawn Rothe en David Kauzlarich (2017) is met zijn 279 bladzijden wat bescheidener van opzet, maar het volgt wel hetzelfde stramien, met dien verstande dat in dit boek ook ruimte wordt gemaakt voor een drietal bijdragen over pogingen 'crimes of the powerful' te reguleren. 
Er is geen eenduidige definitie van 'crimes of the powerful', maar het cruciale punt is dat het criminaliteit betreft die juist niet uit tekortkomingen ontstaat en ook geen ongelukkig exces is bij een verder legitieme gezagsverhouding, maar juist veroorzaakt wordt door een structureel ongelijke machtsverhouding. Zonder dat de auteurs die hebben bijgedragen aan dit themanummer expliciet spreken in termen van 'crimes of the powerful' kan hun analyse van de gedragingen van met name bankiers en politici wel als zodanig worden begrepen.

Vanaf de laatste economische crisis, die rond 2008 begon, is er veel te doen over de cynische bedrijfscultuur bij banken, accountancy firma's en belastingadviseurs en trustkantoren waarin op amorele wijze wordt gesproken over de wijzen waarop men klanten dubieuze 'financiële producten' kan aansmeren, tot het faciliteren van het witwassen van crimineel geld (en het onvoldoende controle daarop uitoefenen), tot het parasiteren op de belastingbetaler, om direct nadat de banken door de overheid waren 'gered' weer mega-bonussen uit te keren en hoge winsten op te strijken, terwijl de gewone burger, zeker in Zuid-Europese landen, nog lang niet uit de crisis was.

In zijn boek Dit kan niet waar zijn schetst de onderzoeksjournalist Joris Luyendijk (2015) een ontluisterend beeld van het gebrek aan moreel besef in de financiële sector, waarin alles draait om 'scoren', waarin de eigen 'kaste' superieur wordt geacht en klanten 'muppets' worden genoemd. Met dit beeld in het achterhoofd hoeft het ons niet te verbazen dat geld van het corrupte bouwconcern Odebrecht, waardoor in Latijns-Amerika al vele door het bedrijf omgekochte politici en ondernemers op de vlucht zijn geslagen, tot zelfmoord zijn gedreven of achter de tralies zijn beland, ook via Nederlandse banken en trustkantoren naar belastingparadijzen is doorgesluisd. ${ }^{3}$ De vraag of we deze praktijken wel 'criminaliteit' kunnen noemen, is al zo oud als het begrip witteboordencriminaliteit zelf. Toen Edwin Sutherland dit begrip in 1940 muntte, werd ook al gesteld dat het geen criminaliteit was, omdat het niet onder enige strafbepaling te brengen zou zijn. Inmiddels vinden de meeste criminologen die legalistische opvatting niet meer zo relevant voor de beoordeling van dergelijke praktijken. Het feit dat het vaak nog legaal is ook, dat het 'lawful but awful' is, zoals Nikos Passas (2005) het noemde, wordt tegenwoordig juist eerder gezien als een bevestiging van het feit dat de overheid vooral de belangen van de economische elites dient.

In haar bijdrage tot dit themanummer over 'crimes of the powerful' gaat Anna Merz in op de vraag of de machtsongelijkheid die bij een effectieve labelling volgens de theorie zou zijn vereist in het huidige tijdsgewricht, waarin met name bankiers en CEO's van grote, multinationale ondernemingen van vele kanten van onethisch gedrag worden beschuldigd en sociale media de machtsverhoudingen aardig hebben veranderd, nog wel opgaat. Is de kring van 'moral entrepeneurs' niet zoveel groter geworden, dat ook de labelling van 'crimes of the powerful'

3 Zie: www.nrc.nl/nieuws/2019/11/20/die-verdachte-miljoenen-deden-bij-abn-amro-geen-lampjebranden-a3981091 en www.nrc.nl/nieuws/2019/11/21/henk-van-w-hoefde-het-geld-alleenmaar-door-te-sluizen-a3981160. 
mogelijk is geworden? Zijn de 'delinquente elites' nog wel zo onaantastbaar als Pierre Lascoumes (2013) stelde?

Kunnen wij als academici, als vertegenwoordigers van de middenklasse waar wij uiteindelijk toe behoren, eigenlijk wel toegang krijgen tot de delinquente elites? Misschien moeten we hiertoe eens wat vaker te rade gaan bij onze collega's van financieel, fiscaal of ondernemingsrecht. Daniel Beizsley heeft voor zijn proefschrift onderzoek gedaan bij de Europese Investeringsbank in Luxemburg. In zijn bijdrage tot dit themanummer gaat hij vooral in op de moeilijkheid om toegang te krijgen tot respondenten binnen deze bank en op de ethische dilemma's die hierbij komen kijken. Beizsley stelt in zijn artikel dat als we het onderzoeken en bevragen van de elites belangrijk vinden, we onze heilige huisjes met betrekking tot onderzoeksethiek misschien nog eens tegen het licht moeten houden.

In haar bijdrage beschrijft Marilena Drymioti de gevolgen van de economische en maatschappelijke crisis in Griekenland voor de 'gewone Griek' in termen van structureel, institutioneel en anti-institutioneel geweld. Volgens haar kunnen de verregaande bezuinigingsmaatregelen van de trojka van de Europese Centrale Bank, de Europese Unie en het Internationaal Monetair Fonds worden getypeerd als structureel 'gewelddadig', omdat zij de bestaanszekerheid van vele Grieken fundamenteel hebben ontwricht. Hiermee koppelt zij de discussie over 'crimes of the powerful' aan verschillende ideeën over geweld. In haar theoretische exercitie beschouwt zij geweld vooral als een dynamiek tussen agency en de structuur waarin geweld ontstaat, waarbij zowel culturele als contextuele aspecten van geweld dienen te worden betrokken.

In de academische discussies over 'crimes of the powerful' neemt het debat over prostitutie een bijzondere plaats in. Ten eerste moeten we constateren dat de prostituee door criminologen aanvankelijk, in de traditie van het werk van Lombroso en Ferrero over vrouwelijke delinquenten uit 1885, werd gezien als het archetype van de vrouwelijke misdadiger en dat zij (het is in veruit de meeste gevallen een 'zij') na de opkomst van de feministische criminologie midden jaren zeventig van de vorige eeuw, geleidelijk aan steeds meer werd gezien als een slachtoffer van 'het patriarchaat' in het algemeen en van mensenhandelaren in het bijzonder. Hiermee kwam, zoals Joep Rottier in zijn bijdrage aan dit themanummer laat zien, haar agency ook steeds meer onder druk te staan.

Ten tweede moeten we vaststellen dat in de marxistische traditie, van waaruit het begrip 'crimes of the powerful' is ontstaan, prostitutie vooral wordt beschouwd - ook door bijvoorbeeld Willem Bonger (1905) - als een van de weinig overblijvende opties voor met name alleenstaande vrouwen, die van veel andere sectoren op de arbeidsmarkt worden uitgesloten. Dit staat haaks op het hedendaagse, liberale idee dat sommige vrouwen 'kiezen' voor een 'baan' als sekswerker. Volgens Joep Rottier laat de Nieuw-Zeelandse ervaring zien dat de sociale beweging van sekswerkers aldaar, de NZPC, erin is geslaagd om, ondanks het stigma op sekswerk en de discriminatie van sekswerkers, de weerstand van binnen- en buitenlandse tegenstanders van prostitutie en de veronderstelde 'wilsonbekwaamheid' 
van een gemarginaliseerde groep als sekswerkers, de percepties binnen het dominante publieke en politieke debat over prostitutie te wijzigen.

In de rubriek Voorbij de horizon neemt Marc Cools ons mee naar het Berlijn van 1929. Aan de hand van de televisieserie Babylon Berlin laat hij zien waarom Berlijn voor (cultureel) criminologen altijd zo'n fascinerende stad is gebleven.

Dina Siegel voert ons in de rubriek Significant others verder oostwaarts, naar Sint Petersburg wel te verstaan, waar zij met de Russische criminoloog Yakov Gilinsky spreekt over de positie van de criminologie in de voormalige Sovjet-Unie en over hoe het de Russische criminologie daarna is vergaan.

In de rubriek Doka ten slotte zijn twee door René van Swaaningen in maart 2015 in Athene gemaakte foto's opgenomen, die de diepe onvrede over de rol die de financiële sector in het Griekse bezuinigingsbeleid verbeelden. Veel Grieken hebben het beleid van de 'trojka' gezien als 'crimes of the powerful'.

\section{Literatuur}

Agozino, B. (2003), Counter-Colonial Criminology: A Critique of Imperialist Reason. Londen: Pluto Press.

Barak, G. (ed.) (2015), The Routledge International Handbook of the Crimes of the Powerful. Abingdon: Routledge.

Bianchi, H. (1980), Basismodellen in de kriminologie. Deventer: Van Loghum Slaterus.

Bittle, S., L. Snider, S. Tombs \& D. Whyte (eds.) (2018), Revisiting Crimes of the Powerful: Marxism, Crime and Deviance. Abingdon: Routledge.

Boekhout van Solinge, T. (2010), Deforestation crimes and conflicts in the Amazon. Critical Criminology, 18(4), 263-277.

Bonger, W.A. (1905), Criminality and Economic Conditions. Boston: Little, Brown, and Company [1916].

Brants, C. (2007), Gold Collar Crime. In: H.N. Pontell \& G.L. Geis (ed.), International Handbook of White Collar Crime. New York: Springer, 309-326.

Chambliss, W. (1989), State-organized crime. The American Society of Criminology Presidential Address. Criminology, 27(2), 183-208.

Engels, F. (1845), The Condition of the Working Class in England. Londen: Project Gutenberg eBook.1943.

Fijnaut, C.J.C.F. (2014), Criminologie en strafrechtsbedeling: Een historische en transatlantische inleiding. Antwerpen/Den Haag: Intersentia/Boom.

Friedrichs, D.O. (2010), Trusted Criminals: White Collar Crime in Contemporary Society. Belmont CA: Wadsworth.

Green, P. \& T. Ward (2004), State Crime: Governments, Violence and Corruption. London: Pluto Press.

Hebberecht, P. (1984), De kriminologische wetenschap en de studie van de primaire kriminaliseringsprocessen; een overzicht en bespreking van het theoretisch en empirisch onderzoek van de primaire kriminaliseringsprocessen (diss. Universiteit Gent).

Hillyard, P., C. Pantazis, S. Tombs \& D. Gordon (red.) (2004), Beyond Criminology: Taking Harm Seriously. Londen: Pluto Press. 
Lascoumes, P. (2013), Élites délinquantes et résistance au stigmata: Jacques Chirac et le syndrome Teflon. Champs Pénal, vol. X, https://journals.openedition.org/champpenal/ 8388 .

Luyendijk, J. (2015), Dit kan niet waar zijn. Amsterdam: Atlas Contact.

Marx, K. (1842), Debates on the Law on the Theft of Wood. Marxists Internet Archive, www.marxists.org/archive/marx/works/download/Marx_Rheinische_Zeitung.pdf.

Mills, C.W. (1951), White Collar: The American Middle Classes. New York: Oxford University Press.

Mills, C.W. (1956), The Power Elite. New York: Oxford University Press.

Nagel, W.H. (1976), De tijd en de kriminoloog (afscheidsrede Universiteit Leiden). In: W.H. Nagel, Het betrekkelijke van kriminaliteit. Alphen a/d Rijn: Samsom 1977.

Passas, N. (2005), Lawful but awful: 'Legal Corporate Crimes'. The Journal of Socio-Economics, 34(6), 771-786.

Pearce, F. (1976), Crimes of the Powerful: Marxism, Crime and Deviance. London, UK: Pluto Press.

Ross, E.A. (1907), Sin and Society: An Analysis of Latter-Day Iniquity. Boston: Houghton Mifflin Company.

Rothe, D.L. \& D. Kauzlarich (2017), Crimes of the Powerful: An Introduction. Abingdon: Routledge.

Schwendinger, H. \& J. Schwendinger (1970), Defenders of Order or Guardians of Human Rights. Issues in Criminology, 5(2), 123-157.

Smart, C. (1976), Women, Crime and Criminology: A Feminist Critique. Londen: Routledge \& Kegan Paul.

Sutherland, E.H. (1949), The White Collar Criminal. In: V.C. Branham \& S.B. Kutash (ed.), Encyclopedia of Criminology. New York: Philosophical Library.

Taylor, I., P. Walton \& J. Young (1973), The New Criminology: For a social theory of deviance. Londen: Routledge \& Kegan Paul.

Tittle, C.R. (1995), Control Balance: Towards a General Theory of Deviance. Boulder CO: Westview.

Vegh Weis, V. (2018), Marxism and Criminology: A History of Criminal Selectivity. Chicago: Haymarket. 